\title{
Surface Deposition Method; A Novel Protein Immobilization Procedure on a Sensor Surface
}

\author{
Tomohiko YAMAZAKI, Nozomu YASUTAKE, and Koji SODE* \\ Department of Biotechnology, Tokyo University of Agriculture and Technology (2-24-16, Nakamachi, Koganei, Tokyo \\ 184-8588, Japan)
}

Received May 2, 2000 ; Accepted July 31, 2000

\begin{abstract}
A novel immobilization method, surface deposition method, for a membrane-binding protein on the solid surfaces of the sensor is described. We focused on the hydrophobicity of a membrane-binding region of a membrane-binding protein for this immobilization method. The surface deposition method consists of two steps; the first step is the protein adsorption on support surfaces by electrostatic interaction, and the second step is the deposition of the hydrophobic region of a membrane-binding protein onto the surfaces. The surface deposition method can immobilize a protein on solid surfaces under milder conditions than typical protein immobilization methods such as cross-linking and covalent binding. We also constructed a novel amperometric glucose sensing system employing membrane-binding PQQ glucose dehydrogenase using the surface deposition method.
\end{abstract}

Key Words : Protein Immobilization Procedure, Membrane Binding Protein, Pyrroloquinoline Quinone, Glucose Dehydrogenase, Amperometric Biosensor, Colorimetric Biosensor

\section{Introduction}

The immobilization of an enzyme on solid surfaces is an important step for the development of novel biosensors and bioreactors. Covalent binding, adsorption, entrapment and cross-linking are representative immobilization methods for connecting a biological component, such as an enzyme and antibody, onto a support. Although they provide the strong, irreversible bond between proteins and solid surfaces, these methods caused the inactivation of the enzyme. In addition, these methods may be unsuitable for the mass-production of disposable sensors, considering the complicated procedure.

Membrane-binding proteins such as an ethanol dehydrogenase, a methanol dehydrogenase, a fructose dehydrogenase, an aldehyde dehydrogenase and a glucose dehydrogenase $(\mathrm{GDH})$ have been paid attention as amperometric enzyme sensor constituents. GDHs possessing pyrroloquinoline quinone (PQQ) as their prosthetic group do not utilize oxygen as an electron acceptor during the glucose oxidation reaction. It is highly valuable for their application in diagnostics. Furthermore, the authors have been carrying out research on a protein engineering approach in order to construct an ideally engineered PQQGDH, which possesses superior properties, co-factor binding stability, ${ }^{1-4)}$ thermal stability ${ }^{4-6)}$ and substrate specificity. ${ }^{4,7}$ ) Therefore, they are paid attention to the application for the glucose enzyme sensor constituent of an electron-mediator type glucose sensor, instead of glucose oxidase. ${ }^{8,9}$ However, due to the difficulties in handling membrane binding hydrophobic pro-

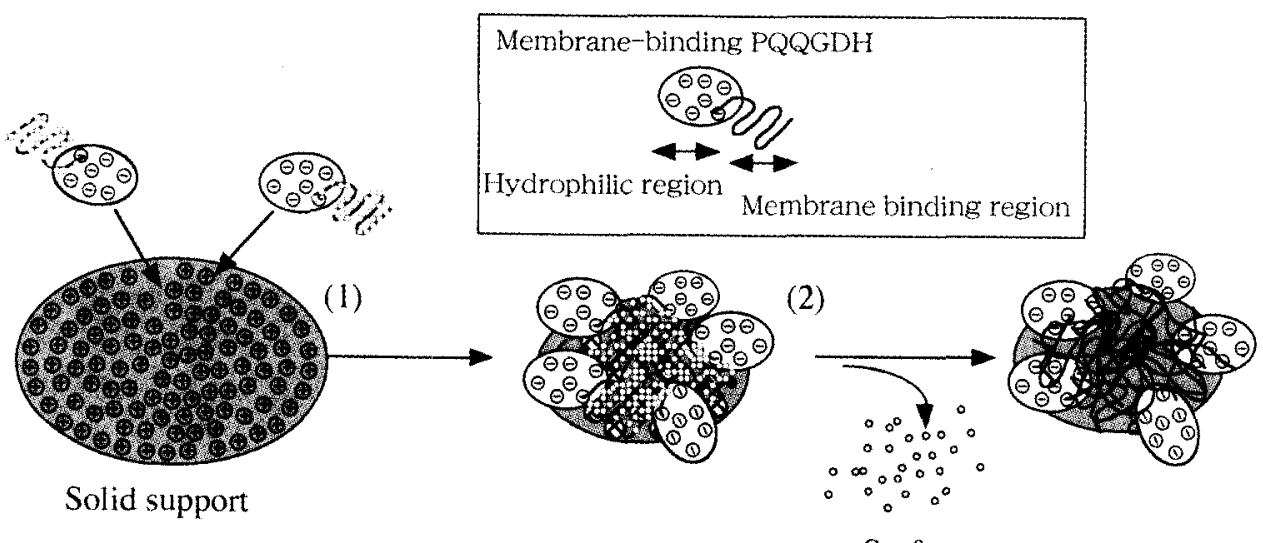

Surfactants

Fig. 1 Scheme of the immobilization of membrane-binding proteins, PQQGDH, on support surfaces using the surface deposition method. (1) Protein adsorption process used for interaction between the positively charged DEAE group on the surface and a negatively charged PQQGDH. (2) Surfactant removing process on the surface of support. 
teins, the application of a membrane binding protein has been limited.

Here we proposed a novel immobilization procedure for membrane-binding proteins, the surface deposition method, which can achieve the surfactant-less assay condition. In this study, membrane-binding PQQGDH is used to investigate the immobilization of membrane binding proteins. Figure 1 shows a schematic illustration of the procedure for the surface deposition method. PQQGDH is composed of two distinct regions, one is the membrane-binding region having a hydrophobic membrane anchoring the helix region and the other is a hydrophilic catalytic region. ${ }^{10,11}$ First, PQQGDH is adsorbed on the solid surface with electrostatic interaction. In the second step, a hydrophobic region of $\mathrm{PQQGDH}$ is deposited on the solid surface by removing surfactant from the solution. The application of the novel immobilization procedure for the construction of the amperometric glucose sensor was also demonstrated.

\section{1 Reagents}

\section{Experimental}

All the chemicals used in this work were reagent grade. Nitro blue tetrazolium (NBT), 2,6-dichlorphenolindophenol (DCIP) and phenazine methosulfate (PMS) were purchased from Kanto Chemicals (Tokyo, Japan). 1methoxy PMS (m-PMS) was obtained from Dojin Chemicals (Kumamoto, Japan). Carbon graphite powder was obtained from BAS Co. (Indiana, USA). Mineral oil was purchased from Sigma (Missouri, USA). Ion exchange filter paper, DEAE-filter paper, was purchased from Advantec-Toyo (Tokyo, Japan). Ion exchange resin, DEAE-Toyopearl $650 \mathrm{M}$, was obtained from Tosoh (Tokyo, Japan).

\section{2 Enzyme preparation and assay condition}

In this study, a thermostable PQQGDH, E 97 A 3, which is composed 97\% of the N-terminal of Escherichia coli and the remaining 3\% of Acinetobacter calcoaceticus PQQGDH was used as PQQGDH to investigate the immobilization of membrane binding proteins. E97A3 showed 3-fold and 12-fold increase in a half lifetime at $40^{\circ} \mathrm{C}$ compared with the wild type PQQGDH of $E$. coli and A. calcoaceticus. ${ }^{5}$ Recombinant chimeric PQQGDH, E97A3, used in this study were expressed in E. coli PP 2418 and purified according to our previous study. ${ }^{5}$ The purified enzyme was dialyzed against a $10 \mathrm{mM}$ potassium phosphate buffer (PPB) $(\mathrm{pH} 7.0)$, containing $0.2(\mathrm{w} / \mathrm{v}) \%$ Triton X-100. GDH assay was carried out spectrophotometrically by measuring the reduction of electron acceptor according to our previous study. ${ }^{3}$

\section{3 Immobilization procedure on surface of diethyl aminoethyl (DEAE) filter paper}

The method of membrane-binding protein immobilization is based on adsorption with solid support surfaces by the electrostatic interaction. One $\mathrm{cm}^{2}$ of DEAE filter paper was placed in $1.5 \mathrm{ml}$ micro tube and soaked with $1.0 \mathrm{ml}$ of $10 \mathrm{mM}$ PPB $(\mathrm{pH} 7.0)$ containing $0.2(\mathrm{w} / \mathrm{v}) \%$ Triton X-100. After equilibrated, the DEAE filter was dipped in $1.0 \mathrm{ml}$ of the enzyme solution (containing 1.5 units of chimeric PQQGDH, E97A3) in order to adsorb
PQQGDH based on the negative charge. After incubation for $1 \mathrm{~min}$, the DEAE filter paper was washed with 10 $\mathrm{mM}$ PPB (pH 7.0) several times for removing Triton X100 completely. The concentration of Triton X-100 was measured by a fluorescence spectrophotometer (FL5500, Shimadzu, Kyoto, JAPAN) with an excitation wavelength of $280 \mathrm{~nm}$ and emission peak at $300 \mathrm{~nm}$. After removing Triton X-100, the PQQGDH immobilized DEAE filter paper was soaked with $10 \mathrm{mM}$ PPB (pH 7.0) containing 1.0 $\mathrm{M} \mathrm{NaCl}$ to remove the non-immobilized GDH and then washed with $10 \mathrm{mM}$ PPB (pH 7.0) 3 times. The washing solutions were collected and GDH activity was measured to check the GDH leakage from the DEAE filter paper. The PQQGDH immobilized DEAE filter paper was dipped in $1.0 \mathrm{ml}$ of $5 \mu \mathrm{M} \mathrm{PQQ}, 10 \mathrm{mM} \mathrm{MgCl}, 50 \mathrm{mM}$ trehalose as additives, $1 \mathrm{mM}$ PMS as electron mediator and $0.05 \mathrm{mM}$ NBT as final electron acceptor dissolved in $10 \mathrm{mM}$ PPB (pH 7.0). Then, the PQQGDH immobilized DEAE filter paper incubated at $37^{\circ} \mathrm{C}$ for 1 hour, and it was lyophilized following the previous report. ${ }^{3)}$

2. 4 Construction of glucose enzyme sensor employing PQQGDH immobilized by surface deposition

$200 \mathrm{mg}$ of carbon paste was mixed with $50 \mathrm{mg}$ of TSK DEAE-Toyopearl resin and $40 \mu 1$ of mineral oil, and the mixture was packed into one end of a carbon paste electrode (CPE, $3.0 \mathrm{~mm}$ diameter, BAS Co., Indiana, USA). PQQGDH was immobilized as follows. The derivatized $\mathrm{CPE}$ was dipped in $1 \mathrm{ml}$ of enzyme solution containing 3.2 units of PQQGDH in $10 \mathrm{mM}$ PPB $(\mathrm{pH} 7.0)$ containing $0.2(\mathrm{w} / \mathrm{v}) \%$ TritonX-100 at room temperature for 5 min. Then the PQQGDH adsorbed CPE was immersed in $10 \mathrm{ml}$ of $10 \mathrm{mM}$ PPB ( $\mathrm{pH} 7.0$ ) for 3 min 3 times to completely remove Triton X-100. Then the GDH immobilized CPE was used for measuring glucose.

\section{5 Electrochemical measurement}

An amperometric measurement and cyclic voltamograms were carried out using a Hokuto Denko potentiostat HA-151 and a function generator HB-111 (Tokyo, Japan) using the three electrodes system.

The working electrode (CPE), a reference electrode $(\mathrm{Ag} / \mathrm{AgCl}$ electrode, $\mathrm{BAS} \mathrm{Co}$.$) and a platinum counter$ electrode $(0.5 \mathrm{~mm}$ diameter, Tanaka noble metal Co., Tokyo, Japan) jointed in the cell through holes in the Teflon cover. All measurement was carried out at $25^{\circ} \mathrm{C}$ in the presence of $100 \mathrm{nmol} \mathrm{m}$-PMS as an electron mediator in $10 \mathrm{ml}$ of $10 \mathrm{mM} \mathrm{PPB} \mathrm{(pH} \mathrm{7.0),} \mathrm{containing} 10 \mathrm{mM}$ $\mathrm{MgCl}_{2}$ and $5 \mu \mathrm{M} \mathrm{PQQ}$, and stirred at 250 r.p.m. with a magnetic stirrer. The anodic applied potential for the oxidation of reduced m-PMS was $+100 \mathrm{mV}$ versus $\mathrm{Ag}$ / $\mathrm{AgCl}(3.0 \mathrm{M} \mathrm{NaCl})$ electrode.

\section{Results and Discussion}

\section{1 Immobilization of PQQGDH on a DEAE filter} paper

PQQGDH adsorbed to a diethyl aminoethyl (DEAE) group on filter paper surfaces due to the negative charge of PQQGDH. Since DEAE-Toyopearl resins are utilized at $\mathrm{pH} 7.0$ in the purification process of $\mathrm{PQQGDH},{ }^{5}{ }^{\prime} \mathrm{E} 97$ A3 adsorbed to DEAE filter paper on the same condition as its purification process. After removal of surfactant, 
TritonX-100, in the DEAE filter paper, the membranebinding region of $\mathrm{PQQGDH}$ might deposit. No leakage of PQQGDH was observed in the washing buffer, $10 \mathrm{mM}$ PPB (pH 7.0) containing $1 \mathrm{M} \mathrm{NaCl}$. Therefore, it is proved that PQQGDH was immobilized on the surface of the DEAE filter paper strongly. The amount of PQQGDH immobilized on the DEAE filter paper was calculated from the difference in the activity of PQQGDH solutions before and after the DEAE filter paper dipping. The quantity of $P Q Q G D H$ on the DEAE filter paper was increased by the area of DEAE filter paper, and PQQGDH was immobilized 1.9 units per $1 \mathrm{~cm}^{2}$ of the DEAE filter paper. We recently reported that by the proteolytic digestion by tripsin of PQQGDH resulted in two peptide fragments; a hydrophobic membrane binding region and a hydrophilic catalytic region. ${ }^{27}$ The resulted hydrophilic catalytic region alone showed dye-mediated PQQGDH activity. Considering that the enzymatic activity of thus prepared hydrophilic region alone was lower than that of whole enzyme, the membrane binding region may have a significant role in expressing whole catalytic activity of this enzyme. Therefore, the immobilized PQQGDH based on the deposition of membrane binding region might express lower catalytic activity compared with that in the solubilized status.

The PQQGDH immobilized DEAE filter paper can be utilized for the colorimetric glucose sensing. Dropping glucose solution on the PQQGDH immobilized DEAE filter paper, the color development immediately occurred and blue color due to reduced NBT was observed.

3. 2 Glucose enzyme sensor employing GDH immobilized by surface deposition

An amperometric glucose sensor was constructed using the surface deposition method. Carbon paste was used as electrode material and mixed with DEAEToyopearl resins to achieve surface deposition immobilization of PQQGDH. The immobilization procedure took about 10 min to immobilize PQQGDH on the electrode surface.

The addition of glucose solution in the cell resulted in a current increase. The steady state current observed 10 to $30 \mathrm{sec}$. The carbon paste enzyme electrode without DEAE-Toyopearl resins, on which PQQGDH was immobilized by absorption, showed less of a response to glucose compared with surface-deposition immobilizing GDH.

Figure 2 shows the typical calibration curve of the PQQGDH immobilized CPE response to glucose. A good linear correlation between the current increase and glucose concentration was observed from 0.1 to $1.0 \mathrm{mM}$. According to the Michaelis-Menten equation, the apparent Michaelis constant $\left(\mathrm{Km}^{\text {app }}\right)$ values for the immobilized GDH were calculated to be $0.9 \mathrm{mM}$, obtained by the Hanes's electrochemical plot based on the data in Fig. 2. The stability during the repeated batch reactions was measured. After 3 times repeated reactions, the PQQGDH immobilized the CPE response to glucose with the same current increase value as the initial operation. Therefore it is considered that PQQGDH was immobilized stably on the surface of the CPE.

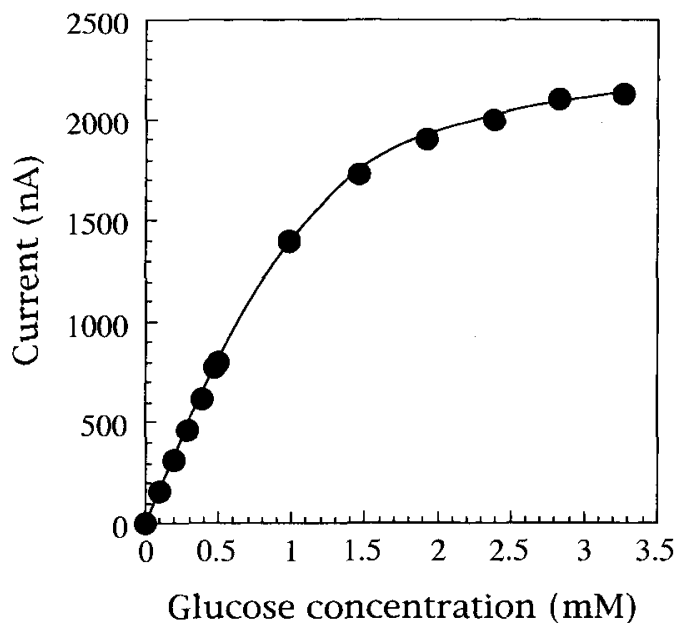

Fig. 2 Calibration curve of the PQQGDH immobilized CPE. Current was measured at $+100 \mathrm{mV}$ versus $\mathrm{Ag} / \mathrm{AgCl}$ (3.0 M $\mathrm{NaCl}$ ), and steady currents were measured in stirred $10 \mathrm{mM}$ PPB $(\mathrm{pH} 7.0)$ at $25^{\circ} \mathrm{C}$.

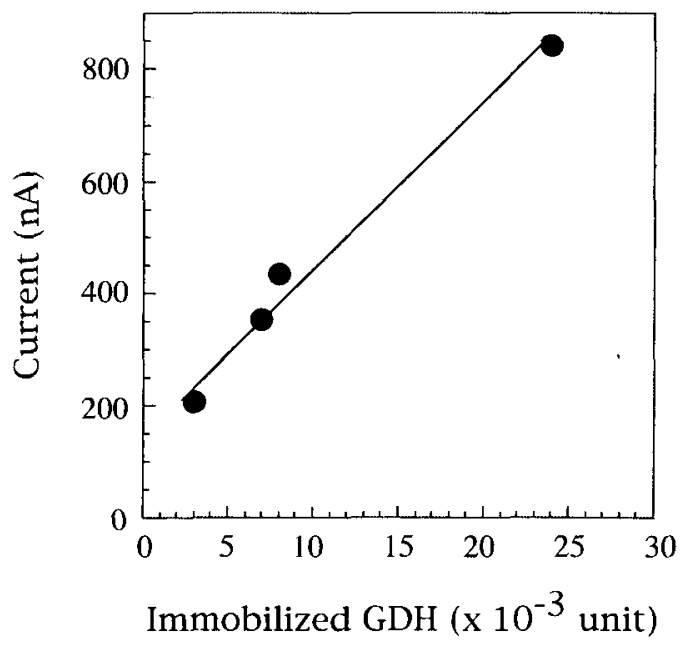

Fig. 3 Relationship between current response of PQQGDH immobilized CPE and amount of immobilized PQQGDH. Immobilized PQQGDH was calculated from the activity of PQQGDH solutions before and after the DEAE filter paper was dipped. $100 \mu \mathrm{l}$ of $100 \mathrm{mM}$ glucose solution was added to the $10 \mathrm{ml}$ assay solution in the cell.

Figure 3 shows the correlation between the amount of immobilized PQQGDH and increased current, adding 1 $\mathrm{mM}$ of glucose in the cell. One unit of immobilized PQQGDH response $29 \mu \mathrm{A}$ to $1.0 \mathrm{mM}$ glucose. So the current response of the enzyme sensor was controlled for the amount of PQQGDH immobilized on the electrode surface. In this paper, we utilized mPMS as the electron mediator. Considering that mPMS is sensitive to the spontaneous oxidation, for the further optimization of mediator for PQQGDH based sensor should be carried out in order to achieve the construction of a stable glucose sensor.

PQQGDH was paid attention as an enzyme sensor constituent for glucose monitoring. Typical protocols for covalent immobilization of membrane-binding PQQGDH on 
the carbon surface require treatment with low $\mathrm{pH}$ and may thus cause its denaturation. ${ }^{13)}$ Other immobilization methods of membrane-binding PQQGDH were adsorption to nitrocellulose filter and cross-linking used glutaraldehyde as bifunctional agent, respectively. ${ }^{8,9)}$ In comparing of these immobilization methods, using the surface deposition method, membrane-binding PQQGDH deposit on the electrode surface under mild conditions. In addition to these benefits, a membrane-binding enzyme was immobilized by simple 'dipping' procedures on solid surfaces. Therefore, the surface deposition method is promising as a method for an effective, reproducible and economic process for the mass-production of disposable biosensor chip.

\section{Conclusion}

In this study, we proposed a novel immobilization method, a surface deposition method, for a membranebinding protein on the solid surfaces of a biosensor, focusing on the hydrophobicity of the membrane binding region. The surface deposition method can immobilize protein on solid surfaces under milder conditions than typical protein immobilization methods such as crosslinking and covalent binding. In this report, applying this novel immobilization method, we have constructed a novel amperometric glucose sensor employing membrane-binding PQQGDH. This new immobilization procedure opens up a new approach to develop biosensors using membrane-binding protein especially.

\section{Acknowledgment}

This work has been financially supported by the Grant,
"Innovative venture business project by graduate students," which is supported and organized by the Venture Business Laboratory (VBL) of Tokyo University of Agriculture and Technology.

\section{References}

1) K. Sode and H. Sano, Biotechnology Letters, 16, 455 (1994).

2) K. Sode and H. Yoshida, Denki Kagaku (presently Electrochemistry), 65, 444 (1997).

3) K. Sode, H. Yoshida, K. Matsumura, T. Kikuchi, M. Watanabe, N. Yasutake, S. Ito, and H. Sano, Biochem. Biophys. Res. Commun., 211, 268 (1995).

4) H. Yoshida, K. Kojima, A. B. Witarto, and K. Sode, Protein Engineering, 12, 63 (1999).

5) K. Sode, K. Watanabe, S. Ito, K. Matsumura, and T. Kikuchi, FEBS Letters, 364, 325 (1995).

6) A. B. Witarto, T. Ohtera, and K. Sode, Applied Biochemistry and Biotechnology, 77-79, 159 (1999).

7) K. Sode and K. Kojima, Biotechnology Letters, 19, 1073 (1997).

8) K. Yokoyama, K. Sode, E. Tamiya, and I. Karube, Analytica Chimica Acta, 218, 137 (1989).

9) K. Sode, S. Nakasono, M. Tanaka, and T. Matsunaga, Biotechnology and Bioengineering, 42, 251 (1993).

10) A. M. Cleton-Jansen, N. Goosen, O. Fayet, and P. J. Van de Putte, Journal of Bacteriology, 172, 6308 (1990).

11) M. Yamada, K. Sumi, K. Matsushita, O. Adachi, and Y. Yamada, J. Biol. Chem., 268, 12812 (1993).

12) A. B. Witarto, S. Ohuchi, M. Narita, and K. Sode, J. Biochem. Mol. Biol. \& Biophys., 2, 209 (1999)

13) M. Smolander, J. Buchert, and L. Viikari, Journal of Biotechnology, 29, 287 (1993). 